\title{
How to improve the safety of bicortical pedicle screw insertion in the thoracolumbar vertebrae: analysis base on three-dimensional CT reconstruction of patients in the prone position
}

Chao Xu' ${ }^{1}$, Qingxian $\mathrm{Hou}^{2}$, Yanchen $\mathrm{CHU}^{2}$, Xiuling Huang ${ }^{3}$, Wenjiu Yang ${ }^{2}$, Jinglong $\mathrm{Ma}^{1}$ and Zhijie Wang ${ }^{2 *}$

\begin{abstract}
Background: Through the comparison of three-dimensional $C T$ reconstruction between the supine position and the prone position, the relative position of thoracolumbar great vessels and vertebral body was studied, and the shortest safe distance between them was measured to improve the safety of bicortical pedicle screw insertion and reduce the risk of vascular injury.
\end{abstract}

Methods: Forty adults were selected to participate the research. Three-dimensional reconstruction of thoracolumbar (T9-L3) CT was performed in the prone position and the supine position. The relative distance between the Aorta/Inferior Vena Cava (IVC) and vertebral body was obtained as AVDNDD respectively. The relative angle of the Aorta/ IVC and the vertebral body was calculated as $\angle A O Y / \angle V O Y$. Self-controlled experiments were carried out in the prone and the supine positions, and the data obtained were analyzed using SPSS 22.0 statistical software.

Results: The AVD of the prone position and the supine position was the shortest at T12 $(3.18 \pm 0.68 \mathrm{~mm})$, but the difference was not statistically significant. The aorta of the T9-L3 segment was shifted from the anterolateral to the anteromedial. The $\angle A O Y$ of the other groups differed significantly between the prone and supine positions in all vertebrae except T12 and L1 $(P<0.05)$, and the aorta in the prone position was more anteromedial than that of supine position.

With regard to WD/LVOY, there was no significant difference between the prone and supine positions $(P \geq 0.05)$, and the minimum WD of L3 segment is greater than $5.4 \mathrm{~mm}$. The IVC has no obvious mobility and is fixed in the range of $20^{\circ} \sim 30^{\circ}$ near the midline.

(Continued on next page)

* Correspondence: simonwang1969@163.com

2Department of Spine Surgery, The Affiliated Hospital of Qingdao University, Qingdao 266555, Shandong, China

Full list of author information is available at the end of the article

C C The Author(s). 2020 Open Access This article is licensed under a Creative Commons Attribution 4.0 International License, which permits use, sharing, adaptation, distribution and reproduction in any medium or format, as long as you give appropriate credit to the original author(s) and the source, provide a link to the Creative Commons licence, and indicate if changes were made. The images or other third party material in this article are included in the article's Creative Commons licence, unless indicated otherwise in a credit line to the material. If material is not included in the article's Creative Commons licence and your intended use is not permitted by statutory regulation or exceeds the permitted use, you will need to obtain permission directly from the copyright holder. To view a copy of this licence, visit http://creativecommons.org/licenses/by/4.0/. The Creative Commons Public Domain Dedication waiver (http://creativecommons.org/publicdomain/zero/1.0/) applies to the data made available in this article, unless otherwise stated in a credit line to the data. 
(Continued from previous page)

Conclusion: When using bicortical anchoring of pedicle screws, it is safe to ensure that the protruding tips of the screw is less than $3 \mathrm{~mm}$. Due to the mobility of the aorta in different postures and individual differences in anatomy, the prone position CT can help doctors to make better preoperative plans and decisions.

Keywords: Pedicle screw insertion, Bicortical anchorage, Thoracic and lumbar spine disease, Aorta, Inferior vena cava, Prone CT three-dimensional reconstruction

\section{Background}

Pedicle screw fixation is currently the first choice for the treatment of thoracolumbar spine diseases [1]. In the process, most clinicians believe that it is appropriate to insert the screw into $80 \%$ of the depth of the bone-screw channel [2, 3].

However, in treating elderly patients, the pedicle screw bicortical fixation is commonly used. The deeper the screw is placed, the larger the contact area between the screw and the bone is, and the stress is dispersed throughout the hard anterior cortex, thus strengthening the screw fixation. The enhanced internal fixation will reduce the screw loosening, displacement and pullout, and improves the success rate of the operation [4-9].

However, this technique is at risk of damaging the blood vessels in the anterior part of the vertebral body [10-12]. To evaluate this risk and safely implement bicortical screw, the present study used imaging to examine the anatomical relationship between the great vessels and the vertebral body, and it also explored ways to improve the accuracy of bicortical fixation and reduce the risk of vascular injury.

\section{Methods}

\section{Participants}

Forty adults were selected to participate in the study: twenty men and twenty women between ages of 21 and 76 with a mean age of 53.4 years old. All participants had no thoracolumbar deformities, major vascular malformations, and anterior thoracolumbar vascular lesions, and none of them had any history of retroperitoneal surgery or thoracolumbar surgery.

\section{Materials}

Computed tomography was carried out by using PHIL IPS brilliance iCT 256-row spiral CT, with PHILIPS

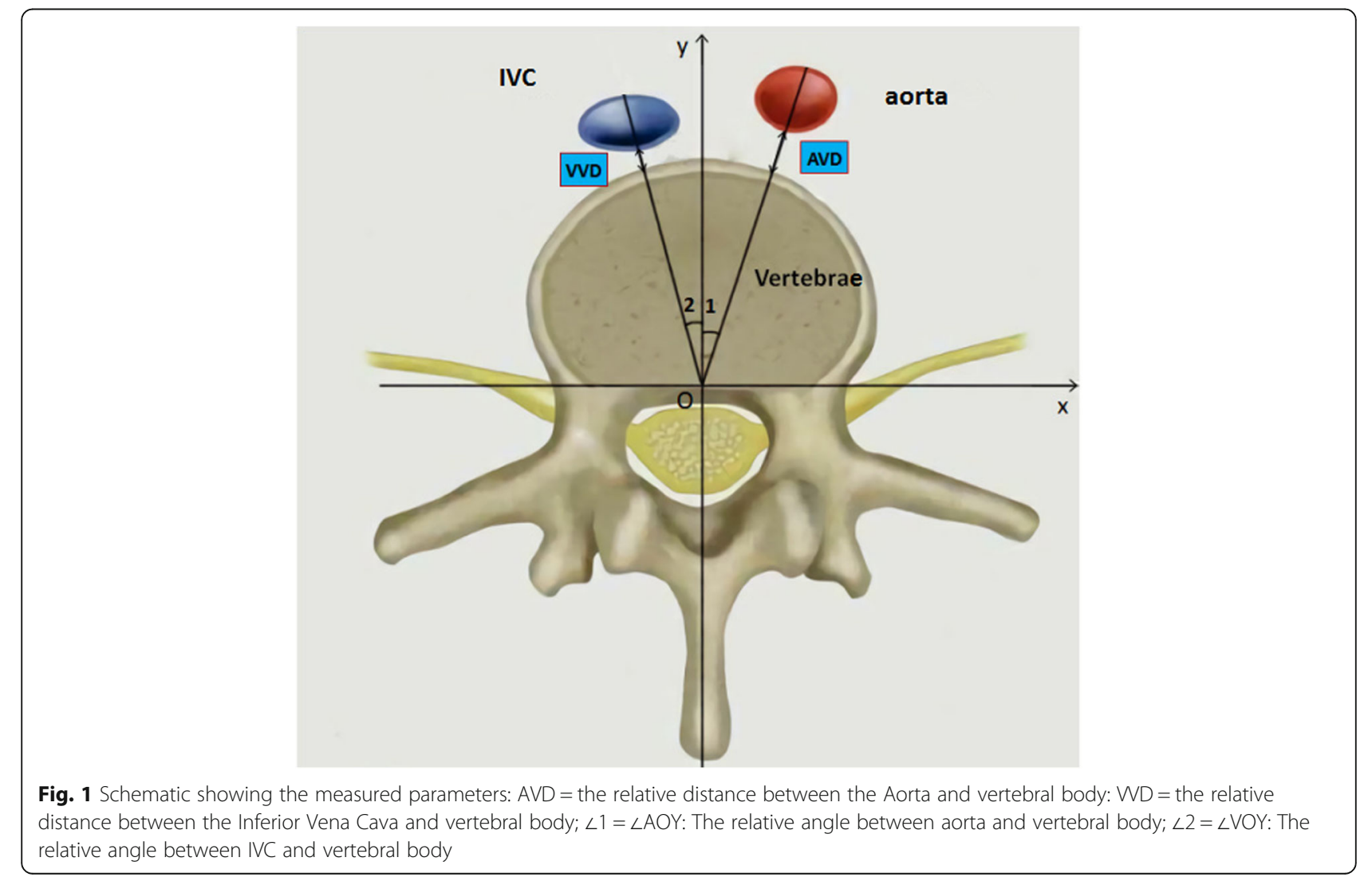


image post-processing system. All subjects were injected with iodine contrast agent, and statistics were analyzed by using SPSS 22.0 statistical software.

\section{Methods}

The thoracolumbar region was reconstructed in three dimensions $\mathrm{CT}$, with the patients in the prone position and the supine position respectively. In order to obtain a clearer image, iodine contrast agent was injected during the scanning process for angiography. The collected images were reconstructed by Philips ICT image postprocessing workstation.

Fig.1 showed the axial image of the optimal pedicle screw trajectory plane. The following measurements were acquired: the angle of great vessels relative to the vertebral body ( $\angle \mathrm{AOY} / \angle \mathrm{VOY}$; Fig. 1$)$, and the shortest distance of between the great vessels and vertebral body in this direction. (AVD/VVD),

The experiment was designed to obtain an axial image of the optimal pedicle screw trajectory plane, which was perpendicular to the posterior plane of the vertebral body. In order to facilitate observation and measurement, the reference line was marked as axis $\mathrm{X}$, axis $\mathrm{Y}$, axis $\mathrm{Z}$, and origin $\mathrm{O}$. The $\mathrm{X}$ and $\mathrm{Z}$ axes passed through the posterior plane of the vertebral body, $\mathrm{X}$ axis passed through the center of the pedicle, and the $\mathrm{Y}$ axis passed through the midline of the vertebral body. (Fig.1, Fig.2).

On the axial plane, the $\mathrm{Y}$ axis was marked as $0^{\circ}$. The $\angle \mathrm{AOY} / \angle \mathrm{VOY}$ of the great vessel refers to the average angle between the tangent point on both sides of the vessel and the origin $\mathrm{O}$ relative to the $\mathrm{Y}$ axis. The AVD/VVD was measured in the direction of the angle of $\angle \mathrm{AOY} / \angle \mathrm{VOY}$. (Fig.3).

Self-controlled experiments were carried out on the changes of posture in the prone and the supine positions. The data obtained were analyzed by using SPSS 22.0 statistical software. When the $P$ value was less than 0.05 , the difference was defined as statistically significant. The experimental data were shown by the table of mean \pm standard deviation. Intra-observer reliability was assessed by calculating the spearman correlation coefficient for repeated measurements.

\section{Results}

The relative position of aorta and vertebral body (AVD/ $\angle A O Y$ ) In the prone and the supine positions, the distance from the aorta to the vertebral body of the T9 L3 segment

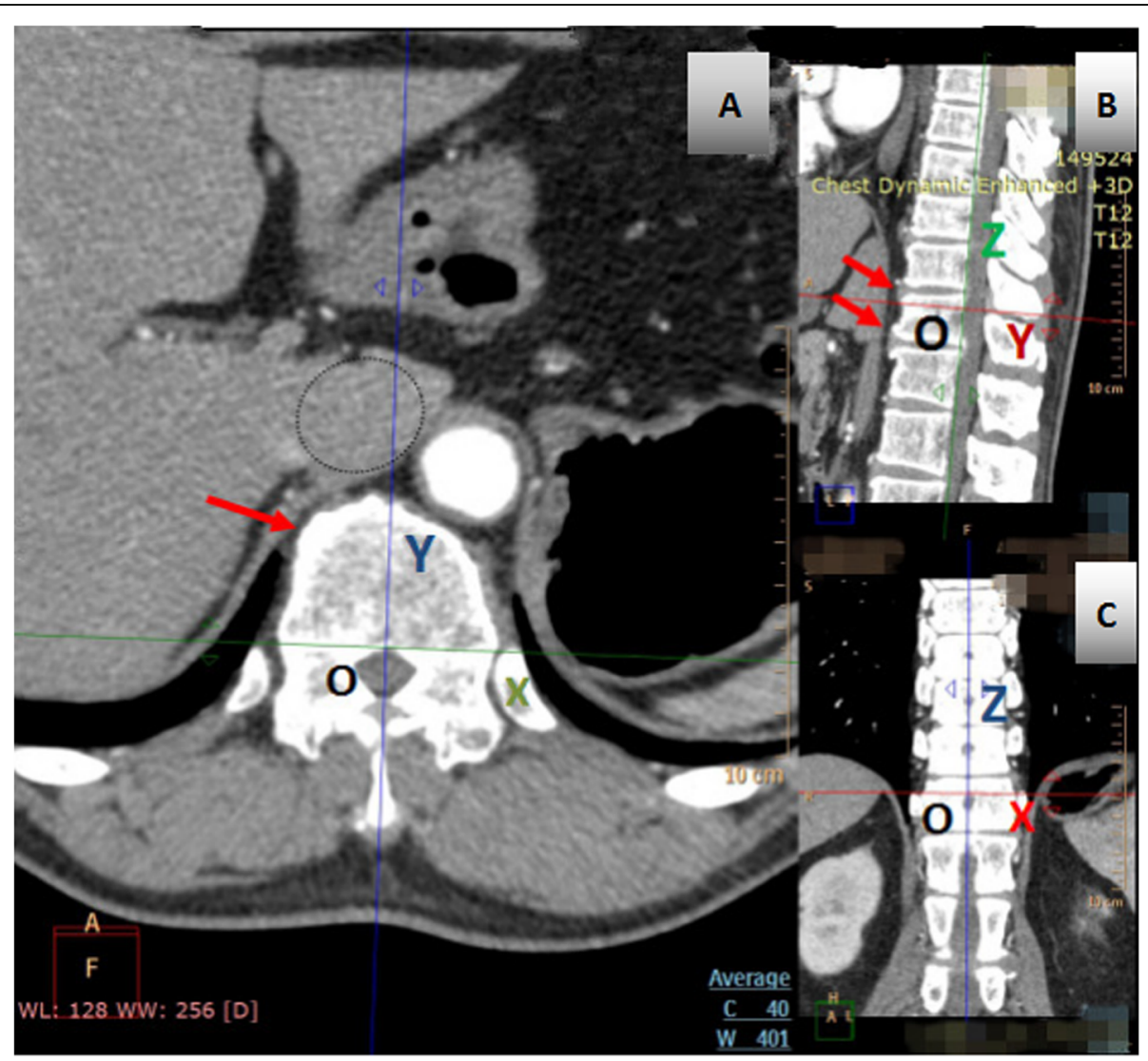

Fig. 2 Schematic showing image localization method for T12 level in the supine position. $\mathbf{a}$, b shows that labial hyperosteogeny may occur on the upper and lower margin of the vertebral body. A shows that the boundary between the IVC and liver tissue passing through the hepatic vena cava sulcus is not obvious 


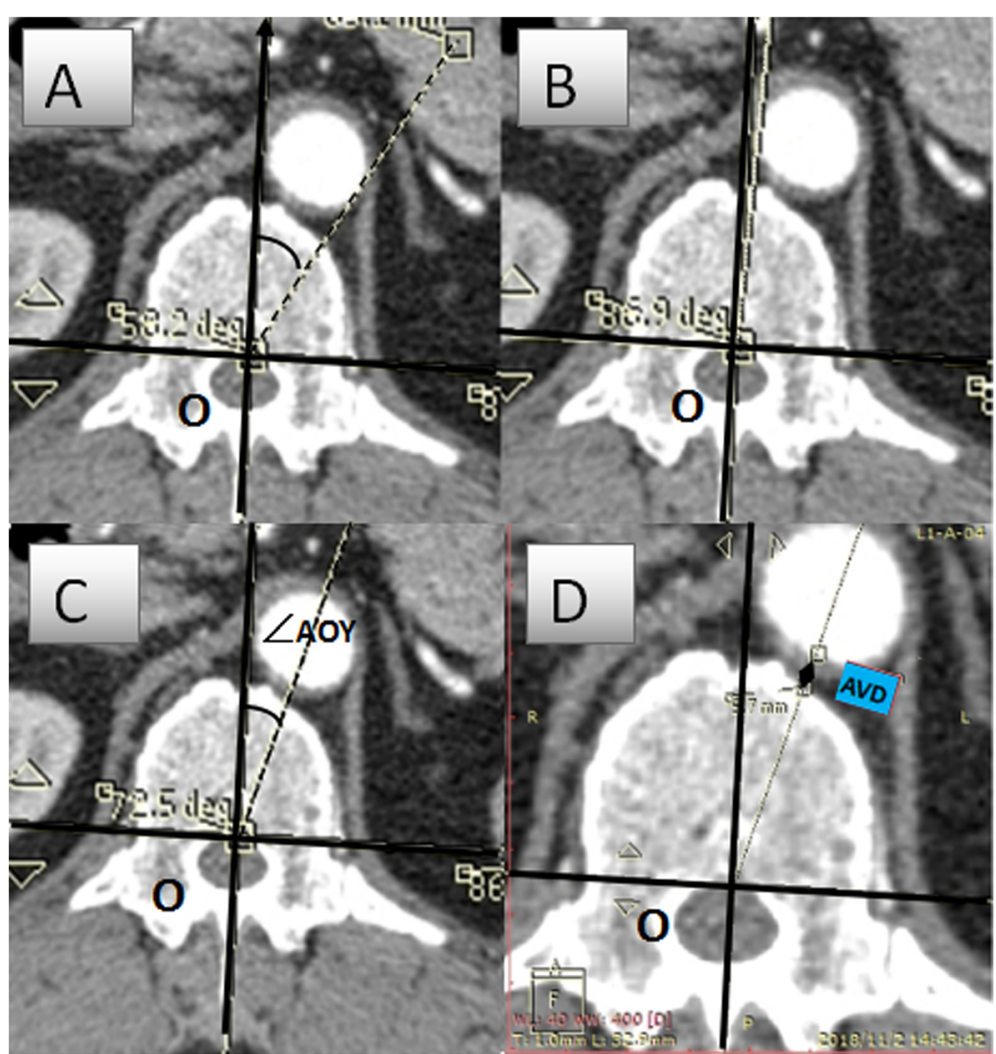

Fig. 3 Schematic diagram of data measurement method

decreased at first and then increased, as shown in Fig.4. In the prone position, the minimum AVD was at T12 which was $3.39 \pm 0.99 \mathrm{~mm}$, followed by L1 which was $3.70 \pm 1.43 \mathrm{~mm}$; the maximum AVD was at T9 which was $5.94 \pm 1.73 \mathrm{~mm}$. In the supine position, the minimum AVD was at T12 which was $3.18 \pm 0.68 \mathrm{~mm}$, followed by L1 which was $3.70 \pm 0.83 \mathrm{~mm}$; the maximum AVD was at L3 which was $5.74 \pm 2.65 \mathrm{~mm}$. The AVD increased more in the prone position than in the supine position, and the AVD values measured at the T9, T10, T11, L2 vertebral bodies differed significantly between the prone and the supine positions $(P<0.05$; Table 1$)$.

In the prone position, the aorta of the T9-L3 segment tended to shift from the anterolateral side of the vertebral body to the anteromedial side of the vertebral body, as shown in Fig. 5, getting closer to the $Y$ axis. At first, the $\angle \mathrm{AOY}$ gradually decreased from the level of $\mathrm{T} 9$ vertebrae $\left(19.47 \pm 10.49^{\circ}\right)$ to the level of T11 vertebrae $\left(11.85 \pm 8.60^{\circ}\right)$. It then increased, and a short peak appeared at the level of T12 and L1 $\left(14.16 \pm 6.84^{\circ}, 14.11 \pm\right.$ $\left.8.71^{\circ}\right)$, and then decreased to the level of L3 $(5.30 \pm 5.68$ $\left.{ }^{\circ}\right)$. In the supine position, the relative angle showed a similar result, the aorta gradually approaching the midline of the vertebral body. (Fig.5). Except for T12 and L1, there were significant differences between the angles of AOY in the prone and the supine positions $(P<0.05)$ (Table 1).

The relative position of IVA and vertebral body (VVD / $/$ VOY) In the prone and the supine positions, the distance between IVA and vertebral body of L1 L3 segment decreased gradually (Fig.6). However, the VVD values measured at the L1-L3 vertebral bodies didn't differ significantly between the prone and supine positions $(P \geq 0.05$; Table 2).

In the prone and the supine positions, the IVA of the L1-L3 segment was located in front of the right anterior side of the vertebral body (Fig. 7). However, it was limited to the $20^{\circ}-30^{\circ}$ position near the midline of the vertebral body ( $\mathrm{Y}$ axis). There was no significant difference in the values of $\angle \mathrm{VOY}$ between prone position and supine position ( $\mathrm{P} \geq 0.05$; Table 2 ).

\section{Intra-observer reliability}

The intra-observer reliability analysis on measurements of the distance and angle showed that the correlation coefficients of AVD/VVD and $\angle A O Y / \angle V O Y$ are 0.95 and 0.93 respectively, representing excellent reliability. 


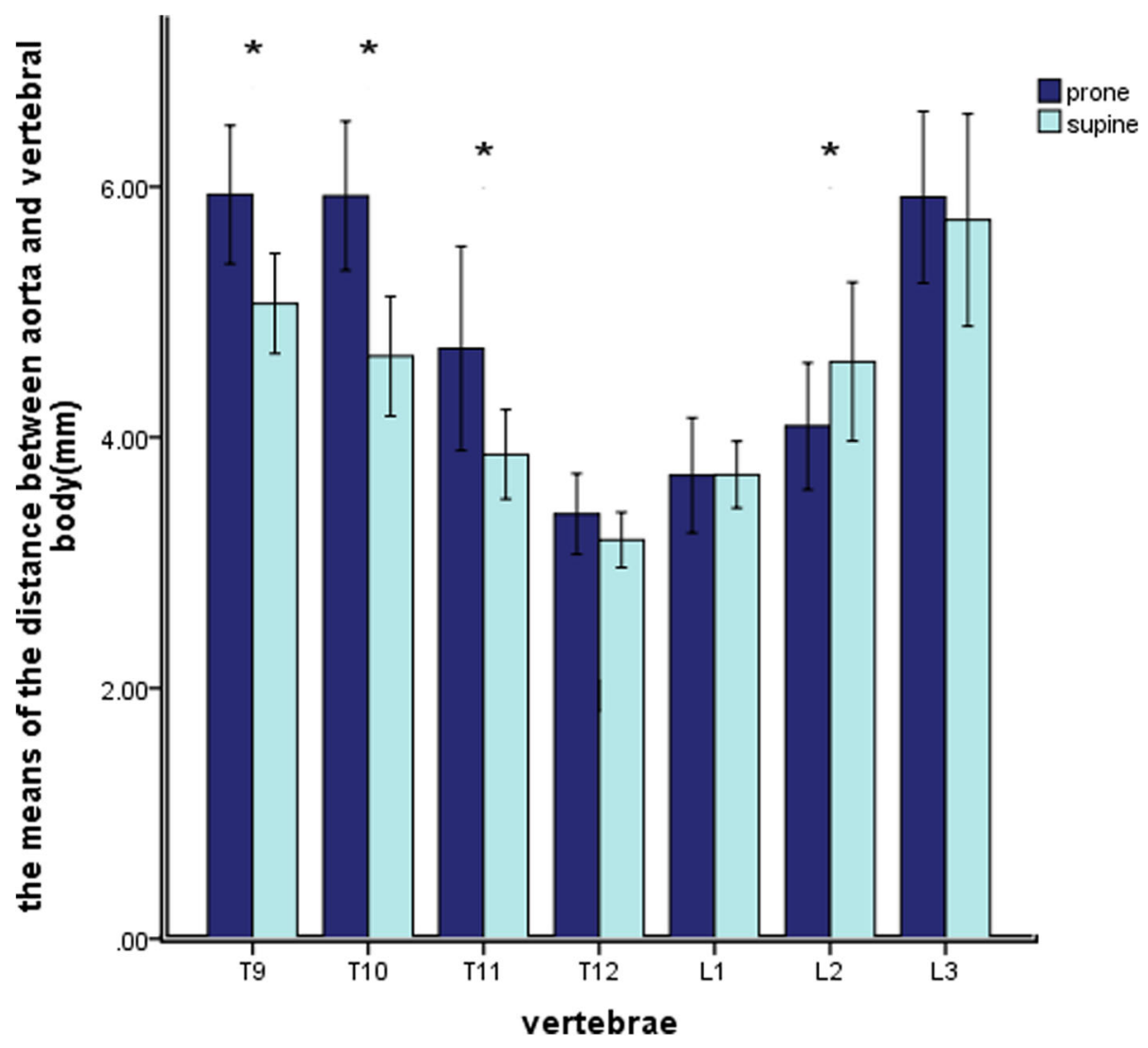

Fig. 4 The value of AVD in the prone and the supine positions. * Means the difference in data is statistically significant

\section{Discussion}

Bicortical fixation requires precise screw placement, as protruding screw tips can damage blood vessels $[13,14]$. The experimental results show that the safe range of the protruding tips of the screw should be kept within the 3 $\mathrm{mm}$. At the same time, due to the change of the relationship between blood vessels and posture, the prone position CT images can provide a more accurate and safe range of screw TSA. This is important for the safe use of pedicle screw bicortical fixation to improve the strength of fixation.
The significance of pedicle screw bicortical insertion

It has been the focus of scholars to enhance the pullout force and internal fixation stability of pedicle screw. Clinicians wisely use bone cement augmentation, cortical bone channels, expandable pedicle and novel screw fixation. These new techniques have achieved satisfactory clinical results for the osteoporosis patient [8, 15-18]. But for patients with non-severe osteoporosis, especially those in the middle-aged and elderly with a certain amount of bone loss, surgical techniques that increase the strength of internal fixation may be a better option,

Table 1 The distance and relative angle between aorta and vertebral body in different positions $\left(\mathrm{mm} /{ }^{\circ}, \mathrm{Mean} \pm \mathrm{SD}\right)$

\begin{tabular}{|c|c|c|c|c|c|c|}
\hline \multirow[t]{2}{*}{ level } & \multicolumn{3}{|l|}{ AVD } & \multicolumn{3}{|l|}{$\angle A O Y$} \\
\hline & Prone & Supine & $P$ value & Prone & Supine & $P$ value \\
\hline T9 & $5.94 \pm 1.73$ & $5.07 \pm 1.25$ & $0.000^{*}$ & $19.47 \pm 10.49$ & $32.07 \pm 11.33$ & $0.000^{*}$ \\
\hline $\mathrm{T} 10$ & $5.93 \pm 1.86$ & $4.65 \pm 1.50$ & $0.000^{*}$ & $18.47 \pm 10.93$ & $22.79 \pm 8.48$ & $0.032^{*}$ \\
\hline T11 & $4.71 \pm 2.55$ & $3.87 \pm 1.11$ & $0.003^{*}$ & $11.85 \pm 8.60$ & $16.19 \pm 8.40$ & $0.000^{*}$ \\
\hline $\mathrm{T} 12$ & $3.39 \pm 0.99$ & $3.18 \pm 0.68$ & 0.091 & $14.16 \pm 6.84$ & $14.83 \pm 6.98$ & 0.412 \\
\hline L1 & $3.70 \pm 1.43$ & $3.70 \pm 0.83$ & 0.983 & $14.11 \pm 8.71$ & $13.80 \pm 7.52$ & 0.605 \\
\hline L2 & $4.09 \pm 1.58$ & $4.61 \pm 1.98$ & $0.001^{*}$ & $10.70 \pm 7.61$ & $13.58 \pm 7.38$ & $0.000^{*}$ \\
\hline L3 & $5.92 \pm 2.14$ & $5.74 \pm 2.65$ & 0.404 & $5.30 \pm 5.68$ & $8.85 \pm 3.80$ & $0.000^{*}$ \\
\hline
\end{tabular}

* Means the difference in data is statistically significant 


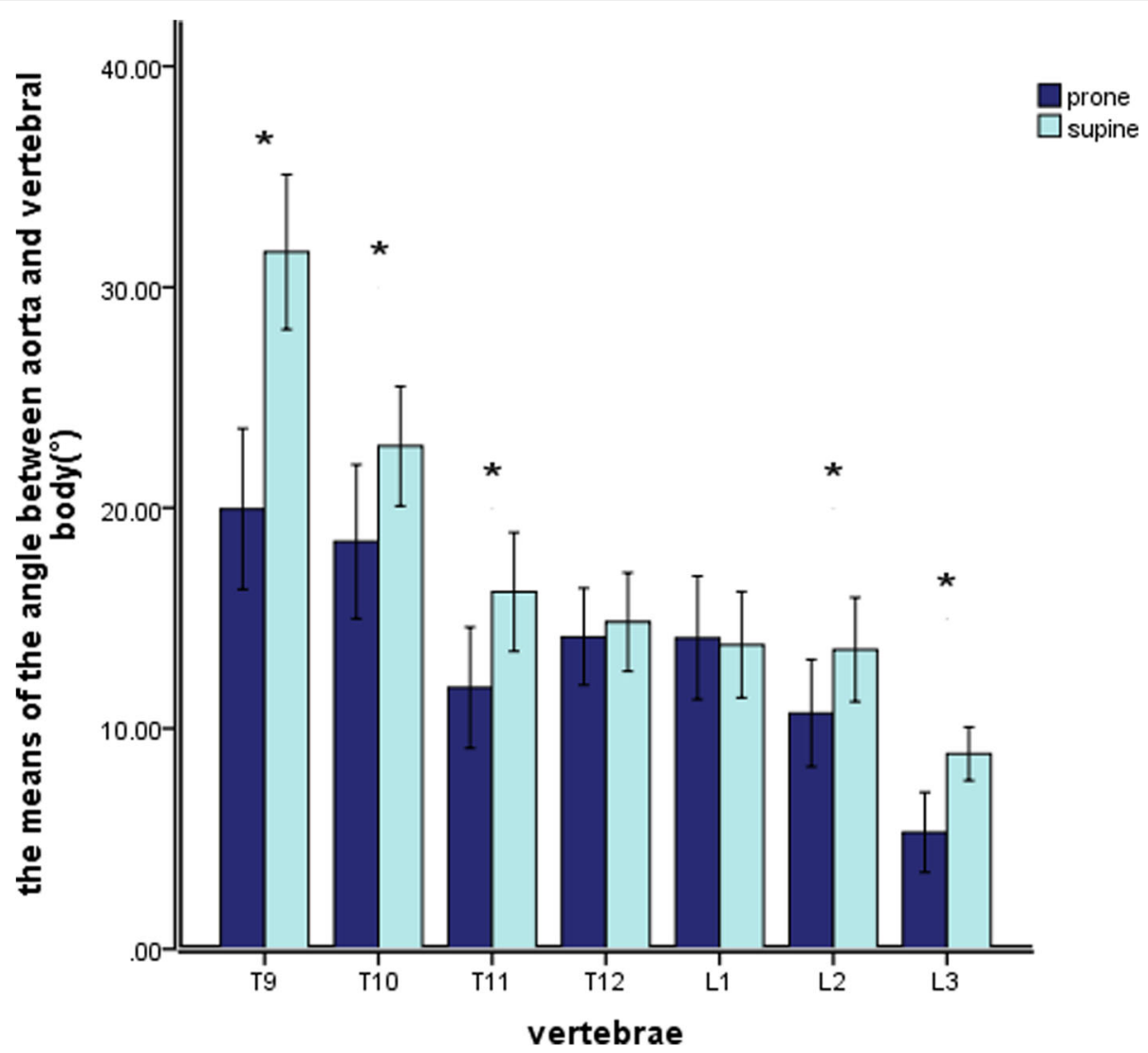

Fig. 5 The relative Angle of the aorta and vertebral body $\angle A O Y$ in the prone position and the supine position. ${ }^{*}$ Means the difference in data is statistically significant

particularly in increasing the diameter of the pedicle screw, the depth necessary for insertion, and the insertion angle show an advantage $[19,20]$.

Studies have shown that when the screw is inserted in the anterior cortex of the vertebral body but not penetrated, the fixation strength can be increased by $16 \%$, and the anterior cortex can be broken through, which can increase the pedicle screw pullout force by $60 \%$ and fixation strength by $20-25 \%$ [21-24]. Bicortical anchorage increases the length of screw insertion and the stress is dispersed between the two cortical bones so that the fixation strength is significantly higher than that of cancellous bone $[4,5]$. Its reliable fixation strength has also served in adolescent idiopathic spinal deformity or spinal deformity.

\section{The effect of body positions on the distance between vertebral body and the great vessel}

Huitema et al. [25] proved a substantial difference in the position of the aorta relative to the spine in the prone and in the supine position (range, T4-L2), while Vaccaro et al. [26] demonstrated substantial mobility of the great vessels in different positions (range, L4-S1). We also verified the results of the aorta, and we found that the AVD of T12 is the shortest distance both in the prone and the supine positions. Considering anatomical factors, the thoracic aorta extends into the abdominal aorta from the aortic sac of the diaphragm, which is mostly located at the T12-L1 positions and is close to the vertebral body. Thus, the aorta and vertebral bodies are fixed at T12 and L1 level and will not change due to changes in body positions. Compared with the aorta, we believe that the mobility of IVC has no obvious changes in different body positions.

\section{Discussion on the safety distance between vertebral body and blood vessel}

Sarwahi et al. [27] claimed that anterior/anterolateral protrusion is less than or equal to $4 \mathrm{~mm}$ on CT poses no significant risk of impingement and can be considered safe. In gross anatomy, 23 misplaced screws do not endanger any structures and the distance they protruded are less than $4 \mathrm{~mm}$ on CT scan [27]. Because of the large distance between the large vessels 


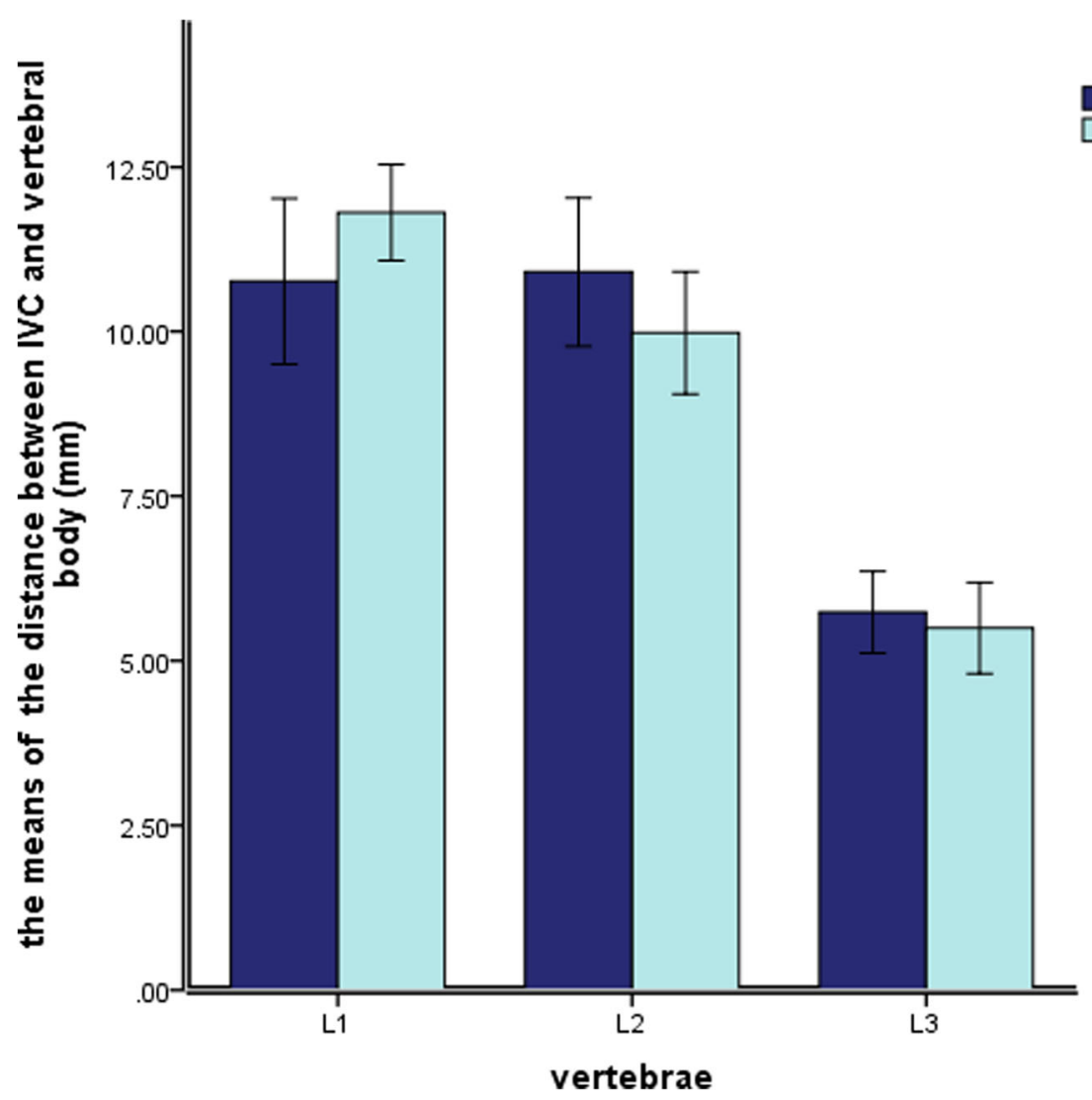

Fig. 6 The value of WD in the prone and the supine positions

and the vertebral body in the prone position, we evaluated and measured the safe distance in the supine position with CT. The shortest distance between the aorta and the vertebra is $3.18 \pm 0.68 \mathrm{~mm}$ at T12, and the shortest distance between the IVA and the vertebra is $5.50 \pm 2.17 \mathrm{~mm}$ at the L3 level. Considering the large distance in the prone position and the poor visualization of soft tissue on CT images, we conservatively believe that it is safe for the protruding tip of the screw to be less than that of $3 \mathrm{~mm}$. Due to individual differences, we recommend that the actual safe distance between the great vessels and the vertebral body can be measured according to our method before surgery. In addition, imaging examination shows that labial hyperosteogeny may occur on the upper and lower margin of the vertebral body in elderly patients, pushing the anterior vertebral vessels to the front of the vertebral body (Fig. 2a), increasing the safe distance between the blood vessel and vertebral body.

When evaluating misplaced screws in contact with blood vessels, the protruding tips of some of the screws are too long, which puts more degrees of impingement on the blood vessels and is more likely to cause chronic vascular injury [28]. There will also be contact between the screw and the blood vessel after the bicortical fixation. However, patients with pedicle screws in contact with major vessels may not necessarily suffer adverse

Table 2 The shortest and relative angle between inferior vena cava and vertebral body in different positions $\left(\mathrm{mm} /{ }^{\circ}, \mathrm{Mean} \pm \mathrm{SD}\right)$

\begin{tabular}{|c|c|c|c|c|c|c|}
\hline \multirow[t]{2}{*}{ level } & \multicolumn{3}{|l|}{ WD } & \multicolumn{3}{|l|}{$\angle V O Y$} \\
\hline & Prone & Supine & $P$ value & Prone & Supine & $P$ value \\
\hline L1 & $10.77 \pm 3.93$ & $11.81 \pm 2.29$ & 0.068 & $27.23 \pm 4.91$ & $26.26 \pm 3.72$ & 0.147 \\
\hline L2 & $10.91 \pm 3.52$ & $9.98 \pm 2.90$ & 0.121 & $29.07 \pm 7.06$ & $27.20 \pm 4.93$ & 0.054 \\
\hline L3 & $5.74 \pm 1.95$ & $5.50 \pm 2.17$ & 0.548 & $24.88 \pm 8.21$ & $23.21 \pm 4.47$ & 0.087 \\
\hline
\end{tabular}




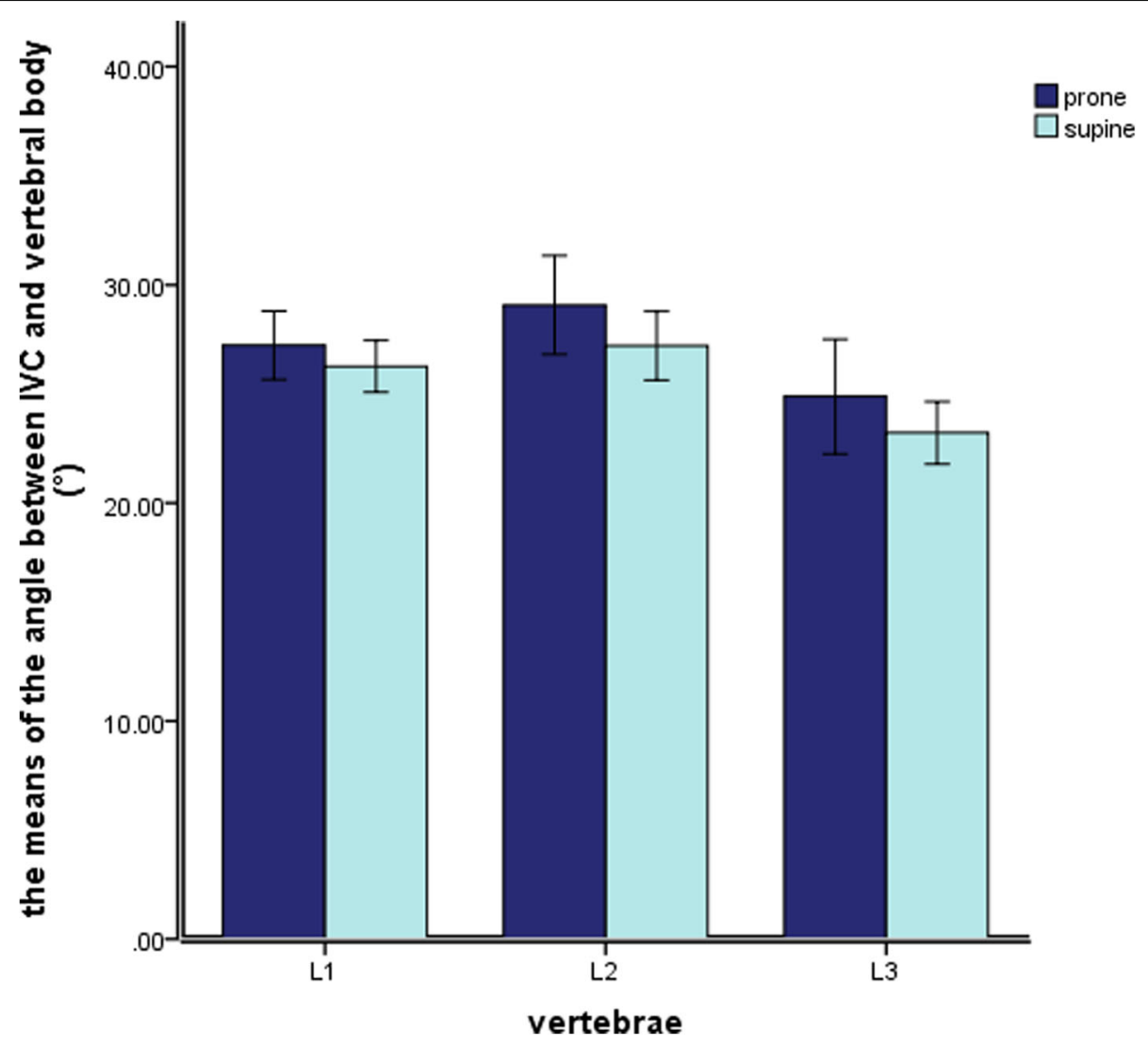

Fig. 7 The relative angle of IVC and vertebral body $\angle \mathrm{VOY}$ in the prone position and the supine position

sequelae [29-31]. We believe that if the tip of the screw can be controlled within the safe range, it will cause a lesser degree of screw impingement into the blood vessels and is unlikely to cause vascular damage [28].

The effect of the angle between the vertebral body and the blood vessel on bicortical fixation of the pedicle screw

Due to individual differences, some segmental vertebrae are close to blood vessels, and there is no obvious safe distance. However, simulating screw placement on preoperative supine and prone CT images can find the appropriate transverse screw angle (TSA), and the screw direction can avoid great vessels completely. As shown in Fig. 8, postoperative CT image of the patients with bicortical fixation presented that the great vessels of the L2 vertebral body can avoid the direction of the screw axis. Liu et.al [32] summarized the appropriate TSA of each pedicle of L1-L4. However, there is still an error in the insertion point of pedicle screw between the preoperative evaluation and the actual operation, which leads to a greater error in TSA. This requires surgeons to build their own preoperative models according to habits and to plan the correct TSA range to reduce errors.

\section{Limitations of this experiment}

This study also had certain limitations, such as a small sample size and inevitable measurement error, although we have chosen angiography CT to minimize errors. We observed that at the level of T8T12, the boundary between the IVC and liver tissue passing through the hepatic vena cava sulcus is not obvious. However, there is a sufficient safe distance between it and the vertebral body, which will not affect the bicortical anchorage at all.(Fig.2) In addition, we also agree that bicortical anchorage is not suitable for implantation of L4-L5 vertebrae [32], and the above relevant data were not collected in the experiment.

\section{Conclusion}

The present data show that it is safe to ensure that the protruding tips of the screw is less than $3 \mathrm{~mm}$ in the treatment of thoracolumbar spinal diseases with pedicle screw bicortical anchorage. When judging the 


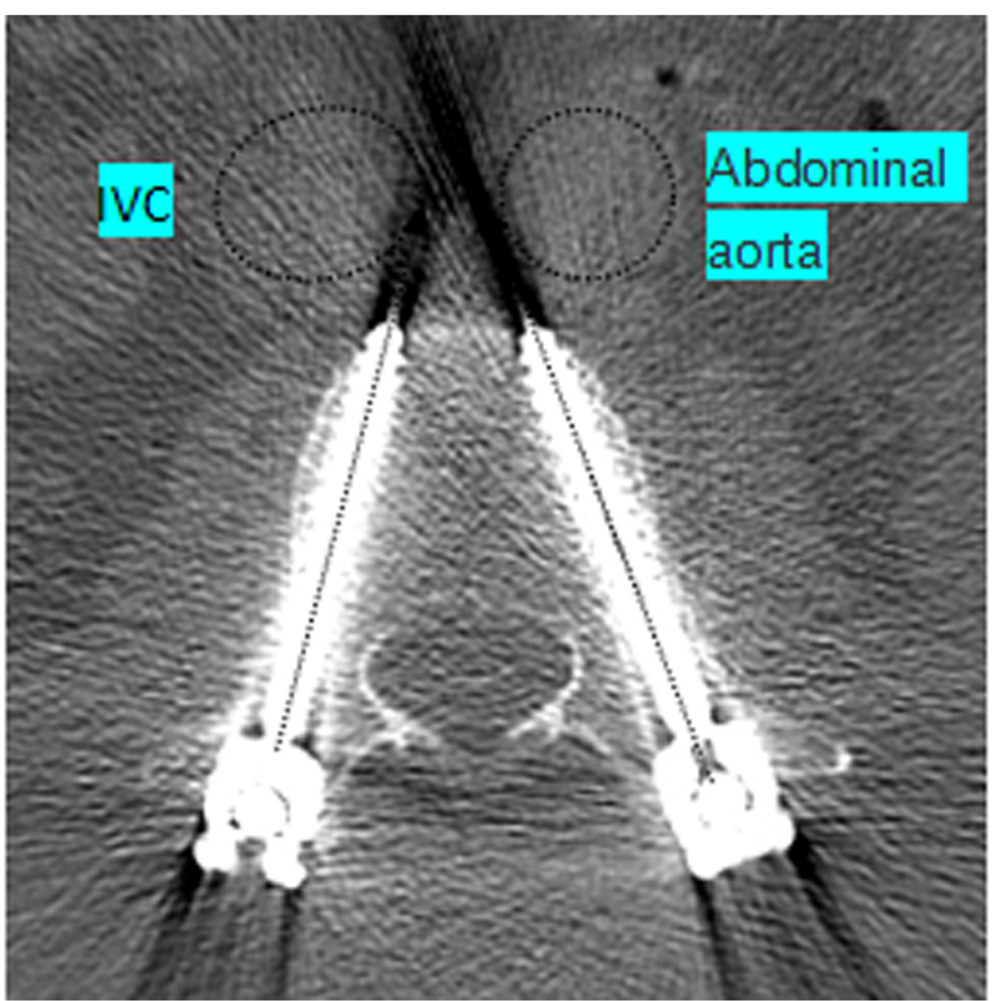

Fig. 8 Postoperative resection of the patients with bicortical fixation revealed that the anterior vessel of the L2 vertebral body avoided the direction of the screw axis

shortest distance, the measurement in the supine position is safer, but the prone position CT should be referred to when choosing the implantation direction TSA. Due to the mobility of the aorta in different postures and individual differences in anatomy, the prone position CT can help doctors to make better preoperative plans and decisions, which is of great significance for safe implementation of the bi-cortical fixation.

\section{Abbreviations}

AVD: Distance between aorta and vertebral body at the T9-L3 level; WD: Distance between IVC and vertebral body at the L1-L3 level; AOY: Angle of position between aorta and vertebral body at the T9-L3 level; VOY: Angle of position between IVC and vertebral body at the L1-L3 level; IVC: Inferior vena cava; TSA: Transverse screw angle

\section{Acknowledgements}

We would like to thank the Department of Radiology, the Affiliated Hospital of Qingdao University and all staff for all of your kindly help and permission to carry out the study.

\section{Authors' contributions}

CX and ZW conceptualized and designed the study. JM Scanned and located images with the help of CX and WY who collected clinical materials. $\mathrm{XH}$ and $\mathrm{CY}$ assisted in data analysis, and CX drafted the manuscript. QH and ZW revised the manuscript. All the authors read and contributed the final manuscript. The author(s) read and approved the final manuscript.

\section{Funding}

This study was financially supported by the Department of Science \& Technology of Shandong Province for Key Technology Research and Development Program of Shandong (CN) (NO. 2018GSF118080) and
Qingdao Municipal Science and Technology Bureau for demotic science and technology program (NO. 19-6-1-16-nsh).

Availability of data and materials

The data used in the current study are available from the corresponding author on reasonable request.

Ethics approval and consent to participate

Before $C T$ scanning, our patients and their family members were informed the risks, and our patients signed an informed consent form; the experimental design met the requirements of the Ethics Committee of the Affiliated Hospital of Qingdao University, NO. QYFYWZLL25636.

\section{Consent for publication}

Not applicable.

\section{Competing interests}

All authors declare that they have no competing interests.

\section{Author details}

${ }^{1}$ Qingdao University Medical College, Qingdao 266071, Shandong, China. 2Department of Spine Surgery, The Affiliated Hospital of Qingdao University, Qingdao 266555, Shandong, China. ${ }^{3}$ Clinical Labororatory, The Affiliated Hospital of Qingdao University, Qingdao, China.

Received: 29 October 2019 Accepted: 2 July 2020

Published online: 07 July 2020

\section{References}

1. Perna F, Borghi R, Pilla F, Stefanini N, Mazzotti A, Chehrassan M. Pedicle screw insertion techniques: an update and review of the literature. Musculoskelet Surg. 2016;100(3):165-9. 
2. Burval DJ, McLain RF, Milks R, Inceoglu S. Primary pedicle screw augmentation in osteoporotic lumbar vertebrae: biomechanical analysis of pedicle fixation strength. Spine (Phila Pa 1976). 2007;32(10):1077-83.

3. Wang XY, Dai LY, Xu HZ, Chi YL. Biomechanical effect of the extent of vertebral body fracture on the thoracolumbar spine with pedicle screw fixation: an in vitro study. J Clin Neurosci. 2008:15(3):286-90.

4. Le Cann S, Cachon T, Viguier E, Miladi L, Odent T, Rossi JM, Chabrand P. Pedicle screw fixation study in immature porcine spines to improve pullout resistance during animal testing. PLoS One. 2015;10(10):e0127463.

5. Karami KJ, Buckenmeyer LE, Kiapour AM, Kelkar PS, Goel VK, Demetropoulos CK, Soo TM. Biomechanical evaluation of the pedicle screw insertion depth effect on screw stability under cyclic loading and subsequent pullout. J Spinal Disord Tech. 2015;28(3):E133-9.

6. Behrend C, George S, Molinari R. Biomechanical evaluation of anterior thoracic salvage screws in the osteoporotic thoracic spine. J Spinal Disord Tech. 2013;26(6):E235-9.

7. Bezer M, Ketenci IE, Saygi B, Kiyak G. Bicortical versus unicortical pedicle screws in direct vertebral rotation: an in vitro experimental study. J Spinal Disord Tech. 2012;25(6):E178-82.

8. Ponnusamy KE, lyer S, Gupta G, Khanna AJ. Instrumentation of the osteoporotic spine: biomechanical and clinical considerations. Spine J. 2011; 11(1):54-63.

9. Mayer M, Stephan D, Resch H, Augat $P$, Auffarth $A$, Blocher M, Ernstbrunner L, Hitzl W, Defossez H, Rouge R, et al. Biomechanical comparison of sacral fixation characteristics of standard S1-pedicle screw fixation versus a novel constrained S1-dual-screw Anchorage in the S1-pedicle and S1-alar bone. Spine (Phila Pa 1976). 2015;40(24):1890-7.

10. Wegener B, Birkenmaier C, Fottner A, Jansson V, Durr HR. Delayed perforation of the aorta by a thoracic pedicle screw. Eur Spine J. 2008; 17(Suppl 2):S351-4.

11. Prabhakar H, Bithal PK, Dash M, Chaturvedi A. Rupture of aorta and inferior vena cava during lumbar disc surgery. Acta Neurochir. 2005;147(3):327-9 discussion 329.

12. Watanabe K, Yamazaki A, Hirano T, Izumi T, Sano A, Morita O, Kikuchi R, Ito T. Descending aortic injury by a thoracic pedicle screw during posterior reconstructive surgery: a case report. Spine (Phila Pa 1976). 2010;35(20): E1064-8.

13. Kato M, Taneichi H, Suda K. Advantage of pedicle screw placement into the sacral promontory (Tricortical purchase) on lumbosacral fixation. J Spinal Disord Tech. 2015;28(6):E336-42.

14. Park YS, Hyun SJ, Choi HY, Kim KJ, Jahng TA. Association between bicortical screw fixation at upper instrumented vertebra and risk for upper instrumented vertebra fracture. J Neurosurg Spine. 2017;26(5):638-44.

15. Guo HZ, Tang YC, Li YX, Yuan K, Guo DQ, Mo GY, Luo PJ, Zhou TP, Zhang SC, Liang D. the effect and safety of Polymethylmethacrylate-augmented sacral pedicle screws applied in osteoporotic spine with lumbosacral degenerative disease: a 2-year follow-up of 25 patients. World Neurosurg. 2019;121:e404-10.

16. Gazzeri R, Roperto R, Fiore C. Surgical treatment of degenerative and traumatic spinal diseases with expandable screws in patients with osteoporosis: 2-year follow-up clinical study. J Neurosurg-Spine. 2016;25(5): 610-9.

17. Demir T. A new alternative to expandable pedicle screws: expandable polyether-ether-ketone shell. Proc Inst Mech Eng H J Eng Med. 2015;229(5):38694.

18. Aycan MF, Yaman ME, Usta Y, Demir T, Tolunay T. Investigation of toggling effect on pullout performance of pedicle screws. Proc Inst Mech Eng H J Eng Med. 2018;232(4):395-402.

19. Hotchkiss WR, Schwend RM, Bosch PP, Edgar HJ, Young BN. Defining the differences in transverse plane trajectories for thoracic pedicle screw insertion: anatomic versus medial. Spine Deform. 2016;4(1):22-6.

20. Varghese V, Saravana Kumar G, Krishnan V. Effect of various factors on pull out strength of pedicle screw in normal and osteoporotic cancellous bone models. Med Eng Phys. 2017:40:28-38.

21. Milcan A, Ayan I, Zeren A, Sinmazcelik T, Yilmaz A, Zeren M, Kuyurtar F. Evaluation of cyanoacrylate augmentation of transpedicular screw pullout strength. J Spinal Disord Tech. 2005;18(6):511-4.

22. Hirano T, Hasegawa K, Takahashi HE, Uchiyama S, Hara T, Washio T, Sugiura T, Yokaichiya M, Ikeda M. Structural characteristics of the pedicle and its role in screw stability. Spine (Phila Pa 1976). 1997:22(21):2504-9 discussion 2510.
23. Zindrick MR, Wiltse LL, Widell EH, Thomas JC, Holland WR, Field BT, Spencer CW. A biomechanical study of intrapeduncular screw fixation in the lumbosacral spine. Clin Orthop Relat Res. 1986;203:99-112.

24. Krag MH, Beynnon BD, Pope MH, DeCoster TA. Depth of insertion of transpedicular vertebral screws into human vertebrae: effect upon screwvertebra interface strength. J Spinal Disord. 1988;1(4):287-94.

25. Huitema GC, Cornips EM, Castelijns MH, van Ooij A, van Santbrink H, van Rhijn LW. The position of the aorta relative to the spine: is it mobile or not? Spine (Phila Pa 1976). 2007:32(12):1259-64.

26. Vaccaro AR, Kepler CK, Rihn JA, Suzuki H, Ratliff JK, Harrop JS, Morrison WB, Limthongkul W, Albert TJ. Anatomical relationships of the anterior blood vessels to the lower lumbar intervertebral discs: analysis based on magnetic resonance imaging of patients in the prone position. J Bone Joint Surg Am. 2012;94(12):1088-94.

27. Sarwahi V, Payares M, Wendolowski S, Gecelter R, Maguire K, Wang D, Thornhill B, Amaral T. Pedicle screw safety: how much anterior breach is safe?: a cadaveric and CT-based study. Spine (Phila Pa 1976). 2017;42(22): E1305-10.

28. Faro FD, Farnsworth CL, Shapiro GS, Mohamad F, White KK, Breisch E, Mahar AT, Tomlinson T, Bawa M, Gomez M, et al. Thoracic vertebral screw impingement on the aorta in an in vivo bovine model. Spine (Phila Pa 1976). 2005:30(21):2406-13.

29. Foxx KC, Kwak RC, Latzman JM, Samadani U. A retrospective analysis of pedicle screws in contact with the great vessels. J Neurosurg Spine. 2010; 13(3):403-6.

30. Sarwahi V, Suggs W, Wollowick AL, Kulkarni PM, Lo Y, Amaral TD, Thornhill B. Pedicle screws adjacent to the great vessels or viscera: a study of 2132 pedicle screws in pediatric spine deformity. J Spinal Disord Tech. 2014;27(2): 64-9.

31. Sarwahi V, Amaral T, Wendolowski S, Gecelter R, Sugarman E, Lo Y, Wang D, Thornhill B. MRIs are less accurate tools for the Most critically worrisome pedicles compared to CT scans. Spine Deform. 2016:4(6):400-6.

32. Liu L, Wang H, Wang J, Wang Q, Cheng S, Li Y, Jin W, Wang Z, Zhou Q. The methods for inserting lumbar bicortical pedicle screws from the anatomical perspective of the prevertebral great vessels. BMC Musculoskelet Disord. 2019;20(1):380.

\section{Publisher's Note}

Springer Nature remains neutral with regard to jurisdictional claims in published maps and institutional affiliations.

Ready to submit your research? Choose BMC and benefit from

- fast, convenient online submission

- thorough peer review by experienced researchers in your field

- rapid publication on acceptance

- support for research data, including large and complex data types

- gold Open Access which fosters wider collaboration and increased citations

- maximum visibility for your research: over $100 \mathrm{M}$ website views per year

At BMC, research is always in progress.

Learn more biomedcentral.com/submissions 